\title{
The Hand-Add Operator Workload Analysis at Production Workstation With 10 Pulse Method at PT.XYZ
}

\author{
Cut Ita Erliana ${ }^{1}$, Amri Sulaiman ${ }^{1}$, Fajriana Yusuf $^{2}$, Meri Andriani $^{3}$, M Heikal $^{4}$, \\ Henry Aspan ${ }^{5}$, Rozanna Dewi ${ }^{6}$ and Laila Nazirah ${ }^{7}$ \\ \{cutitha@unimal.ac.id\} \\ ${ }^{1}$ Department of Industrial Engineering, Universitas Malikussaleh, Aceh, Indonesia \\ ${ }^{2}$ Department of Informatics, Universitas Malikussaleh, Aceh, Indonesia \\ ${ }^{3}$ Department of Industrial Engineering, Universitas Samudra, Langsa, Indonesia \\ ${ }^{4}$ Department of Management, Universitas Malikussaleh, Aceh, Indonesia \\ ${ }_{5}^{5}$ Department of Management,Universitas Pembangunan Panca Budi, Medan, Indonesia \\ ${ }^{6}$ Department of Chemical Engineering, Universitas Malikussaleh, Aceh, Indonesia \\ ${ }^{7}$ Department of Agroecotechnology, Universitas Malikussaleh, Aceh, Indonesia
}

\begin{abstract}
PT. XYZ is one of company whom produce various food for pet. This research aims to analyze the level of hand-add operator workload at the production workstation. Hand-add operator feel sick at their part of body during 8 workhours. This research using 10 pulse method. The result is workload category at the production workstation is heavy and need repairement immediately.
\end{abstract}

Keywords: Workload, Ergonomic, Work Pulse.

\section{Introduction}

Work has different load depends on variety and duration. All activity need muscle and mind power. It may be an external and internal load. Over workload cause fatigue and disease cause work.

PT. XYZ is one of the companies that produce pet food, there are 8 workhours in 3 shift. Production target is 1900 tons/day. Production workstation has many steps such as measurement, mixing, cooling, filtering, and packing. All the step not always using automatic machine especially in mixing hand-add they using a manual system. Transportation material using hand truck from store to bin mixer.

Hand adds Station include 5 operators, 2 operators are handling material into bin mixer and 3 operators bring material from the store near bin mixer approximately 10 meters with stand and sit position. All the activity need much energy plus it does repeatedly without enough rest hours. This situation makes operators fatigue and cause decreasing productivity.

Based on the background of problems that have been described previously, then the focus of the discussion in this study is how the workload of operators hand add on the production of PT. XYZ.The purpose of this research is to know the workload of hand add operators on the production of PT. XYZ. 
The benefits that the authors expect from this study is to apply the theory of workload analysis of physiology in knowing the workload on hand add in operators PT. XYZ.

\section{Literature Review}

Occupational physiology is the study of the function of the human body at work, the basis of the development of ergonomics. Workload is the burden received by the operator due to the implementation of work. This work load is accepted by the body due to carrying out a work activity. Workload may affect the physiological reactions of operators. Workload is a job that is charged to a good worker in the form of physical burden and mental burden which is his responsibility.

\subsection{Factors Affecting the Workload}

The human body is designed to perform daily work activities. The presence of muscle mass weighing almost more than half the body weight, allows us to be able to move and do the job. Work, on the one hand, has significance for the progress and improvement of achievement, thus achieving a productive life as a purpose in life. On the other hand, work means the body will receive the burden from outside the body. In other words that every job is a burden to the concerned. The burden can be either physical or mental.

Workload or workload is an effort that must be issued by a person to meet the demand of the job. Capacity is the capacity/capacity of the human. This capacity can be measured from the physical and mental condition of a person. The workload is the size (portion) of the limited operational capacity required to perform certain work.From an ergonomic standpoint, any workload received by a person must be appropriate or balanced in both the physical, as well as cognitive, and human limitations of the load. Working ability of a workforce differs from one to the other and depends on the skill level, physical fitness, age and body size of the worker concerned.

That in general the relationship between workload and work capacity is influenced by various factors that are very complex, both internal and external factors.

\subsection{Working Measurement With Physiological Method}

In a physical work, humans will produce changes in oxygen consumption, heart rate, body temperature and changes in chemical compounds in the body.

Physical work is grouped by Davis and Miller namely: (1) Total body-wide work, which uses most muscles typically involves two-thirds or three-quarter of the body's muscles. (2) Work muscles that require energy expenditure because the muscles are used less.(3) Working static muscle, the muscle used to produce the force but without mechanical work requires partial muscle contraction.

Physiological measurement studies are intended to address: (1) New knowledge about human performance.(2) More monitor the behavior or properties of champion athletes.(3) Helping one's physical constraints.

Criteria that can be used to determine the effect of work on humans in a work system, namely: physiology criteria, psychological criteriaand criteria of work, namely: (1) The physiology criteria include the rate of heart rate, oxygen consumption, blood pressure, evaporation rate, body temperature, and chemical composition in the blood. This criterion is 
used to know the changing function of body tools.(2) Psychological criteria include testing the psychological level of the worker, such as the level of saturation, emotion, motivation, attitude and others. Psychological criteria are used to determine the psychological changes that arise during work. (3) Criteria of the work include: the work obtained from the workers. This criterion is used to determine the effect of all working conditions by looking at the work obtained from the worker.

\subsection{Energy Level}

There are three levels of common physiological work: rest, aerobic work limits and anaerobic work. At resting stages of energy expenditure is necessary to maintain a body life called base metabolic rate.

It measures the ratio of oxygen that enters the lungs to the outgoing carbon dioxide. Body weight and surface area are decisive factors expressed in calories/surface /hour area. The average human body weighs $65 \mathrm{~kg}$ and has a surface area of 1.77 meters square requires energy of 1 kilocalorie per minute. Work is called aerobics when the oxygen supply is perfect, the system will be deprived of oxygen and work becomes Anaerobic. This is influenced by physiological activity that can be improved through exercise.

\subsection{Physical and mental work}

Physics work is a work that requires physical energy of human muscles as a source of energy (power). Physical work is also called "manual operation" where the performance of work will depend entirely on the human being that serves as a source of power (power) or work controller. Physical work can also be connoted with heavy work or rough work because it requires a strong human effort during the working period. In the physical work of energy consumption is a major factor that used as a benchmark determinant of weight and light of a job. Broadly speaking, human activities can be classified into physical work and mental work.

While mental work is a work that involves the thought process of our brain. This work will result in mental fatigue when the work is in a long time, not caused by physical activity directly but the result of our brain work.

\subsection{Workload Assessment Based on Working Pulse}

Measurement of pulse during work is a method for assessing cardiovasculair strains. One of the tools that can be used to calculate the pulse is telemetry by using Electro Cardio Graph (ECG) stimulation. If the equipment is not available, it can be recorded manually using stopwatch with 10 pulse method.

The formula calculates the working pulse:

Pulse (Pulse / Minute) $\frac{10 \text { Pulse }}{\text { time calculation }} \times 60$ (1)

The sensitivity of the pulse to the changes in loading received by the body is quite high. The pulse will soon change in tune with the change in loading, either from mechanical, physical or chemical loading.Energy consumption alone is not enough to estimate the physical workload. The use of work pulse to assess the weight of the workload has several advantages, in addition 
to easy, fast and cheap is also not required expensive equipment and the results are quite reliable and do not disturb or hurt people who checked.

Energy consumption alone is not enough to estimate the physical workload. The use of work pulse to assess the weight of the workload has several advantages, in addition to easy, fast and cheap is also not required expensive equipment and the results are quite reliable and do not disturb or hurt people who checked.

Increased pulse rate has a very important role in increasing output from rest to maximum work. Potential increase in pulse rate from rest to maximum work. Defined as Reverse Heart Rate (HR Reverse) expressed in percentage which can be calculated using the following formula:

$\% H R$ Reserv $=\frac{\text { working pulse }- \text { resting pulse }}{\text { maximum pulse }- \text { resting pulse }} \chi 100$

\section{Materials and Methods}

The research methodology contains the steps to be taken during the study and is useful as a reference for systematic action. The research steps undertaken on practical work are as follows:(1) Start, (2) Field Observation,(3) ProblemFormulation, (4)Determining Research Objectives, (5) Data Collection,(6) Data Processing, (7) Analysis of Results,(8) Conclusions and Suggestions.

This research was conducted at PT. XYZ. The research period started in July 2017 until August 2017. The object of this research is the animal feed manufacturing industry with the marketing area to various regions both local and abroad. Data collection techniques used in this study include: (1) Primary DataPrimary data is data obtained through observation with the stakeholders in PT. XYZ. The data collected is the resting pulse and the working pulse of the hand-add operator PT. XYZ, (2) Secondary Data. Secondary data is data obtained from other sources (data that have been obtained and recorded by other party) that is data of raw material, production data, number of employee absentee, data about company establishment, organizational structure, and its business field and production process at PT . XYZ journals related to workload, used to support practical work in solving problems.

Data collection in this research is done by direct observation by measuring pulse nadioperator hand add padabagian production of PT. XYZ.Operation Pulse Measurement Data. The data obtained from the measurement of DNI (Pulse Pulse and DNK (Pulse of Work) can be seen in the following table below:

1. The DNI measurement shall be conducted at 8.00 Western Indonesia Time

2. The 1st DNK measurement was conducted at 9:10 pm

3. The second DNK measurement is done at 10:20 pm

4. The 3rd DNK measurement is done at $11.30 \mathrm{WIB}$. 


\section{Results}

\subsection{Analysis of DNI Calculation Result, DNK andCVL Operator 1}

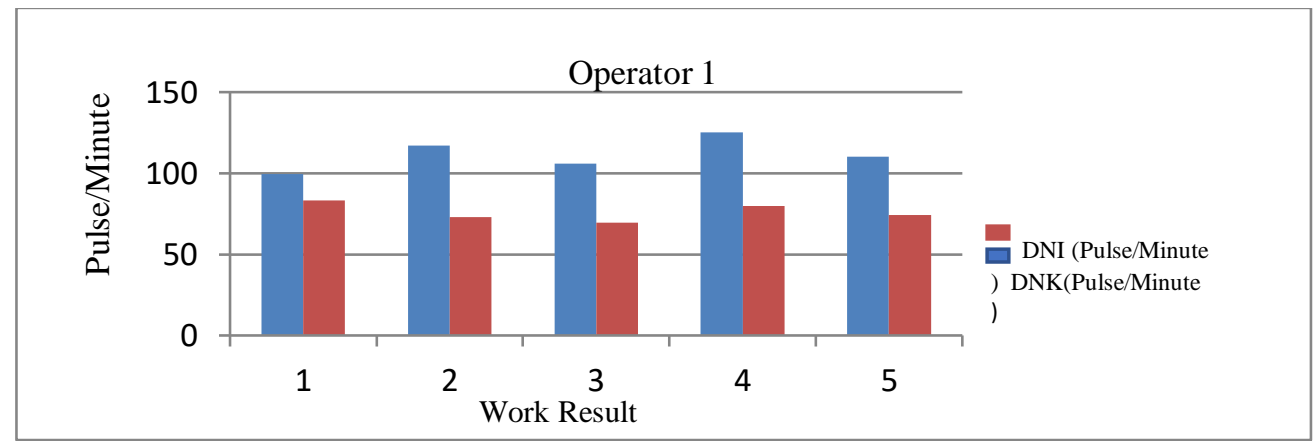

Figure 1. DNI Graph, DNK and CVL Operator 1 For 5 Days

Based on the calculation of the pulse operator 1 who was 24 years old had male gender for 5 days ie on day 1 DNI of 83.44 pulse / minute DNK of 99.37 beats / minute, day 2 DNI of 73.08 pulse / minute DNK equal to 117,01 pulse / minute, day 3 DNI equal to 69,52 pulse / minute DNK equal to 105,73, day 4 DNI equal to 80 beats / minute DNK equal to 125,35 beats / minute and day 5 DNI equal to 74, 07 pulse / minute DNK of 109.99 beats / min and has an average value of 111.49 , is included in the category of medium workload with the classification of 100-125 beats / minute. and with the calculation of cardiovascular results obtained $29.60 \%$ This result belongs to the category acceptable level with the classification\% CVL $<30 \%$.

\subsection{Analysis of DNI Calculation Result, DNK and CVLOperator 2}

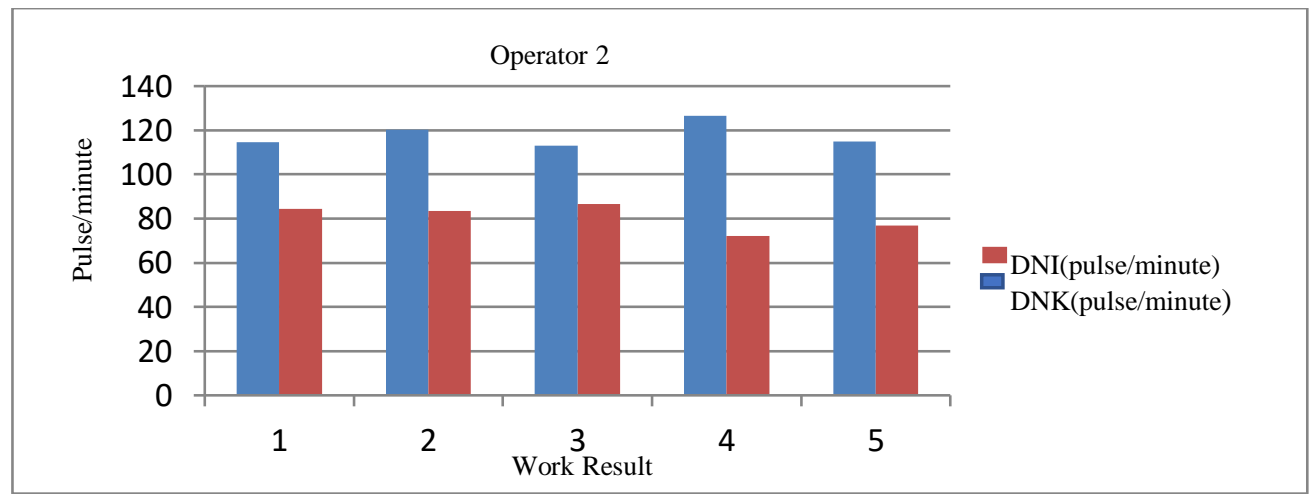

Figure 2. DNI Graph, DNK and CVL Operator 2 For 5 Days

Based on the calculation of the pulse of operator 2 who aged 24 years have male gender for 5 days ie on day 1 DNI of 84.38 beats / minute, DNK day of 114.70 beats / minute, day to 2DNI of 83.79 beats / minute DNK equal to 120,32 beats / min, day to 3DNI equal to 86,58 pulse / minute DNK equal to 112,99 beats/minute, day to 4DNI equal to 72,28 pulse/minute DNK equal 
to 126,51 beats/minute, day 5 DNI of 76.92 pulse / minute DNK of 114.82 beats / min and has an average value of 117.86 , is included in the category of medium workload with the classification of 100-125 beats / minute. and with the calculation of cardiovascular results obtained $31.89 \%$ This result belongs to the category of moderate level with a classification of $30 \%<\mathrm{X}<60 \%$.

\subsection{Analysis of DNI Calculation Result, DNK and CVL Operator 3}

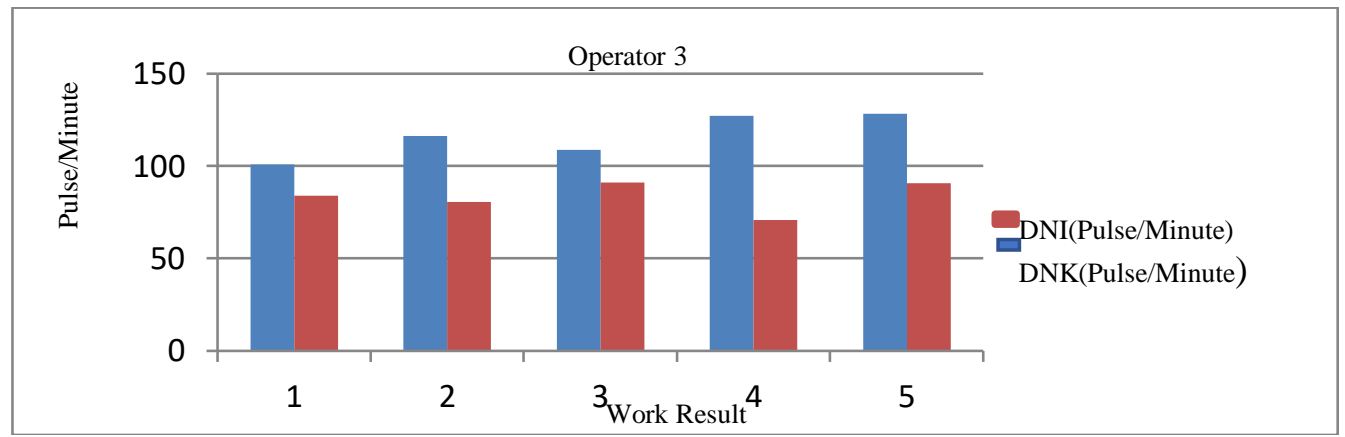

Figure 3. DNI Graph, DNK and CVL Operator 3 For 5 Days

Based on the calculation of the pulse of operator 3 who was 28 years old had male gender for 5 days ie on day 1 DNI of 84.15 beats / minute, DNK of 100.76 beats / minute, day 2DNI of 80.75 beats / minute DNK equal to 116,43 beats / min, day to 3DNI equal to 91,18 pulse / minute DNK equal to 108,85 beats / minute, day to 4 DNI equal to 70,92 pulse / minute DNK equal to 127,03 pulse / minute, day 5 DNI of 90.90 pulse / minute DNK of 128.36 beats / min and has an average value of 116.28 , is included in the category of medium workload with the classification of 100-125 beats / minute. and with the calculation of cardiovascular results obtained $26.97 \%$ This result belongs to the category of moderate level with a classification of $30 \%<\mathrm{X}<60 \%$.

\subsection{Analysis of DNI Calculation Result, DNK and CVL Operator 4}

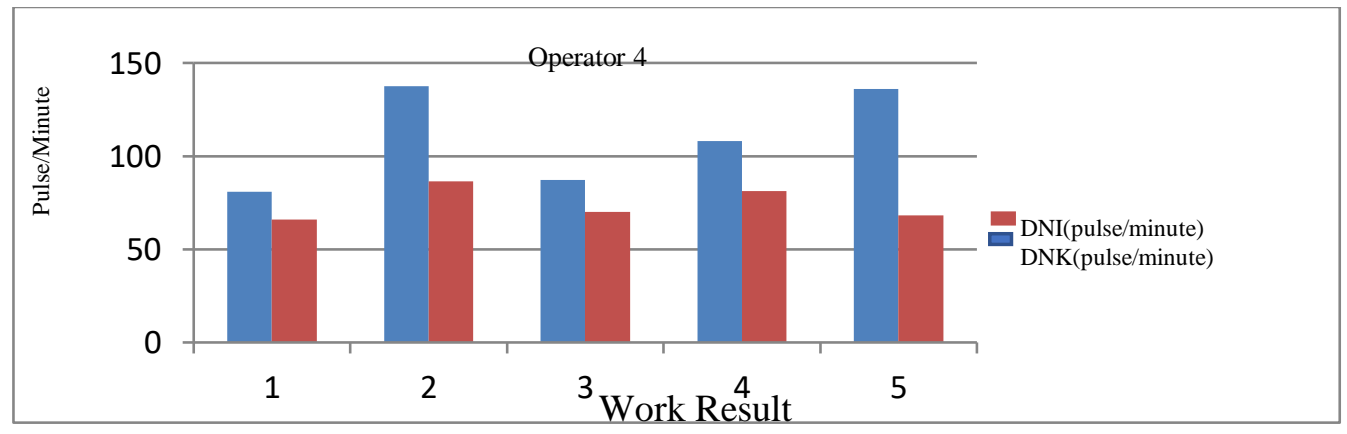

Figure 4. DNI Graph, DNK and CVL Operator 4 For 5 Days 
Based on the calculation of the operator's 4-year-old pulse rate, the male gender for 5 days is on day $1 \mathrm{DNI}$ of 65.93 beats / minute, DNK day is 81.04 beats / min, day 2DNI is 83.33 beats / min DNK of 137.46 pulse / min, day to 3DNI of 69.93 pulse / minute DNK of 87.27 pulse / minute, day to 4DNI of 81.08 pulse / minute DNK of 107.9 beats / minute, day 5 DNI of 68.18 pulse / minute DNK of 136.16 beats / min and has an average value of 109.996 is included in the category of medium workload with the classification of 100-125 beats / minute. and with the calculation of cardiovascular results obtained $30.23 \%$ This result belongs to the category of moderate level with a classification of $30 \%<\mathrm{X}<60 \%$.

\subsection{Analysis of DNI Calculation Result, DNK and CVLOperator 5}

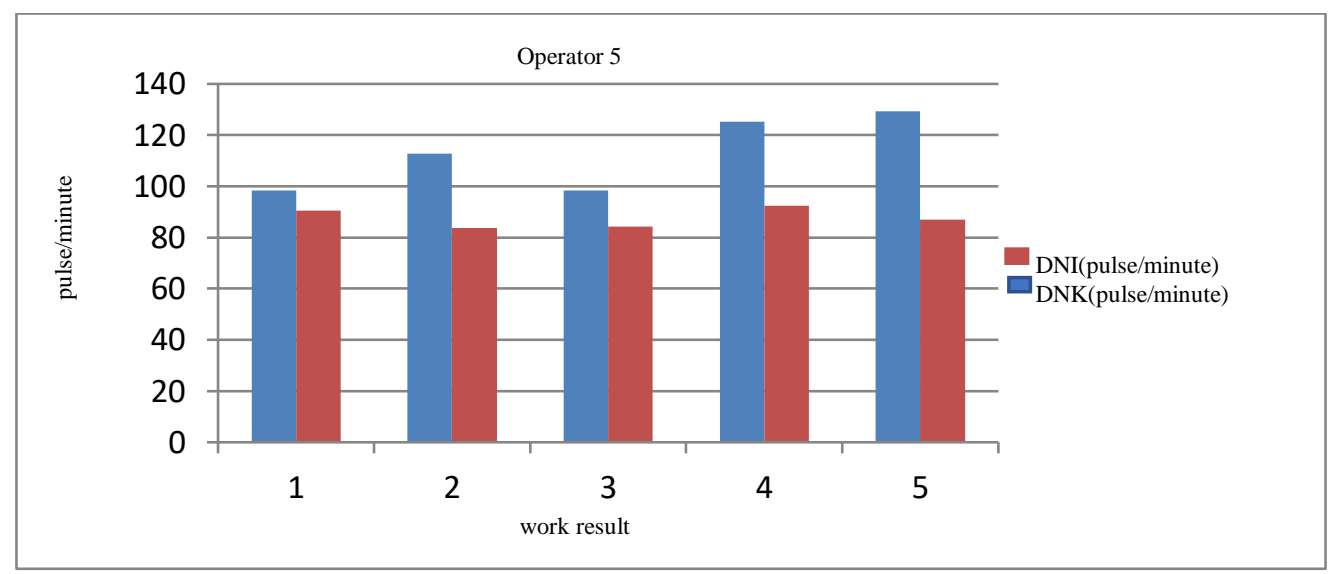

Figure 5. DNI Graph, DNK and CVL Operator 5 For 5 Days

Based on the calculation of the operator's 5-year-old pulse rate, the male gender for 5 days was on day 1 DNI of 90.49 beats / minute, DNK of 98.37 beats / min, day 2nd was 83.79 beats / minute DNK of 112.64 beats / min, day to 3DNI of 84.38 pulse / minute DNK of 98.39 beats / minute, day to 4DNI of 92.44 pulse / minute DNK of 125.14 pulse / min, day 5 DNI equal to 86,95 pulse / minute DNK of 129,27 beats / $\min$ and has average value of 112,76 is included in medium work load category with classification 100-125 beats / minute. and with the calculation of cardiovascular results obtained $23.15 \%$ This result belongs to the category acceptable level with a classification of $30 \%<\mathrm{X}<60 \%$.

\section{Conclusions}

1. Based on the calculation of the pulse operator 1 who aged 24 years have male gender for 5 days then obtained the average pulse rate of 111.49 beats/minute, is included in the category of medium workload with the classification of 100-125 beats/minute and with the calculation of cardiovascular load results obtained $29.60 \%$ This result belongs to the category acceptable level with the classification\% CVL $<30 \%$.

2. Based on the calculation of the pulse of operator 2 who aged 24 years have male gender for 5 days, then obtained the average results of 117.86 pulse / minute, this is included in the category of medium workload with the classification of 100-125 beats/minute and with the 
calculation of cardiovascular load results obtained $31.89 \%$ This result belongs to the category of moderate level with a classification of $30 \%<X<60 \%$.

3. Based on the calculation of the pulse of operator 3 who was 28 years old had male gender for 5 days, then got the average result of 116,28 beats / minute, this included in medium work load category with classification 100-125 pulse/minute and with the calculation ofcardiovascularload obtained results $26.97 \%$ These results fall into the category of acceptable levels with a classification of $30 \%<X<60 \%$.

4. Based on the calculation of the operator's 4-year-old pulse rate has male gender for 5 days, it is obtained an average of 109.996 is included in the category of medium workload with the classification of 100-125 beats/minute and with the calculation of cardiovascularload obtained results $30,23 \%$ This result belongs to the moderate level category with a classification of $30 \%<X<60 \%$.

5. Based on the calculation of the operator's 5-year-old pulse rate of 5 for male sex, the average yield of 112.76 was included in the medium work load category with the classification of $100-125$ beats/min and with the calculation of cardiovascular load obtained results $23.15 \%$ This result is included in the category acceptable level with a classification of $30 \%<X<60 \%$.

\section{References}

[1] Anonimous, 2016. Modul PraktikumAnalisis Perancangan Kerja dan Ergonomi. Department of Industrial Engineering, Universitas Malikussaleh.

[2] Nurmianto, Eko. 1996. Ergonomi: Konsep Dasar dan Aplikasinya.Surabaya: Guna Widya.

[3] Chung, M.K., 1. Lee, D. Kee, 2003. Assessment of postural load for lower limb postures based on perceived discomfort. International Journal of Industrial Ergonomics.January ; 31(1) : 17-32.

[4] Wignosoebroto, S. 2003. Ergonomi Studi Gerak dan Waktu.edisi pertama. cetakan ketiga. Guna Widya, Surabaya

[5] Grandjean, E., 1988. Fitting The Task To The Man. London : Taylor and Francis Ltd. 3 rd Edition.Lientje S. (1994). Relation Between Feeling Of Fatigue, Reaction Time And Work Production. J. Human Ergol. Vol. 24. (1): 129-135 